\title{
Asthma Performance Indicators National Strategies Workshop Proceedings
}

1

\section{ASTHMA PERFORMANCE INDICATOR NATIONAL STRATEGIES WORKSHOP PROCEEDINGS}

Teresa To $\mathrm{PhD}^{1,2,3,4}$, Jacqueline Simatovic $\mathrm{MA}^{1}$

${ }^{1}$ Child Health Evaluative Sciences, The Hospital for Sick Children;

${ }^{2}$ Dalla Lana School of Public Health; ${ }^{3}$ Institute of Health Policy,

Management and Evaluation, University of Toronto; ${ }^{4}$ Institute for

Clinical Evaluative Sciences, Toronto, ON

ACKNOWLEDGEMENT: We extend our gratitude to all attendees of the meeting for their insightful contributions. Attendees included, in alphabetical order: Pat Camp, Brigitte Côté, Mariève Doucet, Nancy Garvey, Charles Gilbert, Wissam Haj-Ali, Jose Mangles, Alan Kaplan, Christopher Licskai, Diane Lougheed, Carole Madeley, Dilshad Moosa, Upal Nath, Rob Oliphant, Sophie Pouliot, Wei Qiu, Jacqueline Quail, Clare Ramsey, Kim Reimer, Joseph Reisman, Michelle Rey, Patricia Sullivan-Taylor, Ann Taite, Itamar Tamari, Pierre Tousignant, Anne Van Dam.

INTRODUCTION: The meeting held on April 10, 2013 in conjunction with the 2013 Canadian Respiratory Conference was organized by Dr Teresa To, Senior Scientist, The Hospital for Sick Children, with support from the Canadian Institutes of Health Research, AllerGen NCE Inc, the Canadian Thoracic Society/Canadian Lung Association, the Ontario Ministry of Health and Long-Term Care and the Ontario Lung Association.

The primary purpose of the meeting was to solicit input and advice from a panel of experts $(n=27)$ knowledgeable and experienced in quality of care and/or asthma performance indicators to develop a national strategy for implementing and evaluating evidence-based indicators for benchmarking and monitoring asthma care in Canada. The following abstracts are presented in the same order as they were during the meeting.

\section{2}

QUEBEC'S USE OF ASTHMA PERFORMANCE INDICATORS

Mariève Doucet $\mathrm{PhD}^{1,2}$, Sophie Pouliot $\mathrm{MA}^{1}$,

Brigitte Côté $M D$ FRCPC $\mathrm{MSc}^{3,4}$, Pierre Tousignant $\mathrm{MD}^{1,5,6}$

${ }^{1}$ Institut national de santé publique du Québec; ${ }^{2}$ Département de médecine, Université Laval, Québec; ${ }^{3}$ Institut national d'excellence en santé et en services sociaux; ${ }^{4}$ Département d'administration de la santé de I'Université de Montréal; ${ }^{5}$ Direction de Santé publique de Montréal; ${ }^{6}$ Centre universitaire de santé McGill, Montreal, QC In the province of Quebec, two institutions have worked on asthma performance indicators (APIs): the Institut national de santé publique du Québec (INSPQ), which has a mandate of chronic disease surveillance and the Institut national d'excellence en santé et en services sociaux (INESSS), which had received a mandate to develop performance indicators (PIs) in primary care for the management of chronic diseases, including asthma in 2009. To fulfill its mandate, the INSPQ developed a respiratory disease surveillance system based on health administrative data. This system focuses on the surveillance of asthma and measures health indicators such as prevalence, incidence, hospitalization and mortality. In the INESSS project, the development process of the PIs included reviewing clinical guidelines to identify evidences of recommended practices and identifying existing PIs (from the National Indicators Clearinghouse and published literature). The dimensions of the chronic care model were used to identify domains for PIs (patient-centeredness, accessibility, evidence-based, continuity and health outcome impact). The selection of PIs was made through a rigorous process that involved consultation with Quebec experts and clinicians, in respiratory diseases in the case of asthma. The characteristics measured included the level of evidence, the pertinence/acceptability for professionals and patients and the measurability of the identified PIs. A list of 23 evidence based APIs was defined and domains covered prevalence of diagnosed disease, drug therapy prescribed, health services utilization and patient-oriented outcomes (1). In the near future, it is expected that APIs will be gradually introduced in Quebec, following an indicator implementation plan put forward by the Ministry of Health. All this process raises many challenges especially linked to measurability and acceptability of PIs.

ACKNOWLEDGEMENT: This project was supported by the Public Health Agency of Canada, through the Canadian Chronic Disease Surveillance System Initiative, the ministère de la Santé et des Services sociaux of Québec and the INSPQ.

\section{REFERENCES}

1. Institut national d'excellence en santé et en services sociaux.

Interactive data base. $<$ http://www.inesss.qc.ca/index.php?id=248>

(Accessed March 8, 2013).

\section{3}

\section{USE OF ASTHMA PERFORMANCE INDICATORS IN NOVA} SCOTIA

\section{Upal Nath PhD}

Community Health and Epidemiology, Faculty of Medicine,

Dalhousie University, Halifax, Nova Scotia

The Population Health Research Unit (http://www.phru.dal.ca/index.cfm) is a university-based research and support group in Nova Scotia that is dedicated to improving the health of the population. This unit does systematic research on population health and health services, as well as collaborates with numerous stakeholders. Despite having a population health research unit and access to multiple population-based databases, the province of Nova Scotia does not currently have an asthma indicators initiative in place. Further, no information exists, even among current research, on the use of asthma performance indicators in the province. Funding for these initiatives is anticipated to be an issue; however, researchers would be interested in future collaborations and contributions to a national platform.

\section{4}

\section{ASTHMA PERFORMANCE INDICATORS IN ONTARIO}

Teresa To $\mathrm{PhD}^{1,2,3,4}$, Jacqueline Simatovic $\mathrm{MA}^{1}$

${ }^{1}$ Child Health Evaluative Sciences, The Hospital for Sick Children, ; ${ }^{2}$ Dalla Lana School of Public Health; ${ }^{3}$ Institute of Health Policy, Management and Evaluation, University of Toronto; ${ }^{4}$ Institute for Clinical Evaluative Sciences, Toronto, ON

Over the past 5 years we have developed an asthma performance indicator (API) tool titled the Primary Care Asthma Performance Indicator (PC-API) Form(C). We are currently evaluating the utility of this form to measure and improve quality of asthma care in Ontario.

In 2008-2009, a comprehensive literature review was completed and a list of 45 performance indicators developed (1). An expert panel $(n=17)$ rated each of the 45 items based on reliability, validity, availability and feasibility. The panel met in person to discuss these ratings and to decide on the top 15 indicators. The indicators were subsequently organized into 9 categories: pulmonary function tests, medication use, asthma control, exacerbations, health care use, action plan, asthma education, smoking cessation and quality of life. These categories were presented in a one-page form (PC-API)

In 2010, an electronic version of the PC-API Form was piloted at 5 primary care sites. Each site collected data from 10 patients and 10 chart abstractions. This pilot test found the PC-API Form $@$ C feasible and easy to use (2).

From 2011-2013, we have used the PC-API Form@ in primary care settings to evaluate quality of care and will be examining the relationship between 
primary care providers' use of performance indicators and patients' use of health care services. Primary care practices $(n=30)$ who see at least 30 asthma patients per annum have been randomly selected to participate in this study. In addition, through the Primary Care Asthma Program (PCAP) Advisory Group, we invited all participating PCAP sites to use the PC-API Form to record asthma quality of care information. These practices will receive a report every 3-6 months summarizing how their site is performing on each indicator as well as how they compare to all sites combined.

CHALLENGES: To move forward at a larger level, funding will be required. Further, integration with exciting EMR system will be necessary to fully engage primary care providers' participation.

FUTURE DIRECTIONS: To develop a national strategy for implementing and evaluating asthma performance indicators.

ACKNOWLEDGMENT: This work was supported by the Government of Ontario, Canadian Institutes of Health Research and the Public Health Agency of Canada. The opinions, results and conclusions reported are those of the author and are independent from the funding sources.

\section{REFERENCES}

1. To T, Guttmann A, Lougheed MD, et al. Evidence-based performance indicators of primary care for asthma: A modified RAND Appropriateness Method. Int J Qual Health Care 2010;22:476-85.

2. To T, McLimont S, Daly C, Moores G, Gershon AS, Lougheed MD. Is it feasible to use indicators to collect data on asthma care performance in the primary care setting? A feasibility study. Prim Care Respir J 2011;20:452-3.

\section{5}

\section{IMPROVING THE QUALITY OF CARE FOR ASTHMA IN} SASKATCHEWAN

\section{Jacqueline Quail PhD}

\section{Health Quality Council of Saskatchewan, Saskatoon SK}

The Health Quality Council (HQC) of Saskatchewan is a governmentfunded independent agency dedicated to improving the quality and experience of health care delivery in Saskatchewan by measuring and reporting on the state of the health care system, promoting improvement, and engaging partners (1). In 2012, the Saskatchewan government began implementing a province-wide patient-focused approach to continuously improve the management and deli very of health care called Lean (2). An essential component of Lean is measurement and HQC currently provides measurement support to all levels of the health care system. In addition to creating indicators and their associated reports, HQC also developed an internet reporting system called Quality Insight Online (QIO) (3). Its purpose is to give everyone - public, health care providers, managers, and leaders - the information they need to understand the current state of the health care system and support quality improvement work to make the system better and safer for Saskatchewan residents. QIO currently boasts 122 indicators relating to a variety of topics including patient experiences with health care, population health, and the health of the workforce. New indicators are added continuously. Indicators are initially reported at the provincial level and can be broken down by health region, facility, and demographic characteristics such as age and sex. Indicators are graphed as basic charts, in which the value of the indicator is plotted over time, and/ or statistical process control (SPC) charts. SPC charts are used to identify when a statistically significant change in the indicator occurs and are commonly used in quality improvement (4).

The HQC published its first report on asthma in 2005 and is currently updating asthma indicators that will be posted on QIO in the summer of 2013. These indicators include asthma prevalence, incidence, and quarterly hospitalization rates. Other asthma quality indicators are currently under development.

\section{REFERENCES}

1. Health Quality Council. <http://hqc.sk.ca/> (Accessed June 17, 2013).

2. Health Quality Council Continuous Improvement: Lean. $<$ http://hqc. sk.ca/improve-health-care-quality/lean/> (Accessed on June 17, 2013).

3. Quality Insight Online. <http://www.qualityinsight.ca/> (Accessed June 17, 2013).

4. Benneyan JC, Lloyd RC, Plsek PE. Statistical process control as a tool for research and health care improvement. Qual Safe Health Care. Dec 2003;12(6):458-464. http://www.ihi.org/knowledge/Pages/Publications/ Statisticalprocesscontrolasatoolforresearchandhealthcareimprovement. aspx

\section{6}

\section{ASTHMA PERFORMANCE INDICATORS IN MANITOBA}

Clare D Ramsey MD MSc FRCPC

Internal Medicine, Faculty of Medicine, University of Manitoba, Winnipeg, MB

In the province of Manitoba, relatively crude asthma performance indicators including the number of admissions to hospital and the intensive care unit for asthma, as well as length of stay have been followed for years. This data is more regularly reviewed in a structured manner in pediatric compared to adult medicine. Asthma admissions to the children's hospital are reviewed on a monthly basis by the pediatric asthma clinic and length of stayed is tracked by the Children's hospital. On the adult side, data on asthma admissions and length of stay are collected, as with all primary reasons for hospitalization; however, this data is not review is a rigorous manner or on a regular basis.

A large amount of data is collected and housed at the Manitoba Centre for Health Policy, including all hospitalizations, length of stay, outpatient physician visits and all dispensed prescription medications in the province. This data has been utilized for publications on asthma prevalence rates and trends over time, as well as medication utilization amongst asthmatics. However, this information has not been rigorously used to date to look at performance improvement measures or initiatives.

Barriers to implementation of asthma performance indicators in Manitoba are that all emergency visits can not be tracked in the province, as several large volume emergency departments are salaried and therefore do not bill visits by disease code, which is the method by which our databases track indication for physician visit or hospitalization. Furthermore as most hospitals in Winnipeg, Manitoba have not transitioned to electronic medical records (EMRs), this data is not readily available in a timely fashion. As all hospitals are moving towards EMRs, this problem should be rectified in the near future.

In terms of future directions, in the past year Manitoba Health has developed a new billing code for chronic disease management of which asthma has been selected as one of the diseases to be piloted in this program. This billing code requires family physicians to provide asthma action plans to all their patients and thus this will be a marker that could be followed over time. To date resources have not been available to regularly follow many of the available asthma indicators, but hopefully through the initiative of this workshop and group, the importance and value of this type of quality improvement initiative will be realized and more broadly supported.

\section{7}

\section{INTEGRATION OF INDICATORS INTO ELECTRONIC MEDICAL RECORDS (EMR): KEY LEARNINGS \& ENABLERS}

\section{Patricia Sullivan-Taylor BSN MPA PMP}

Canadian Institute for Health Information, Ottawa, ON

Canadian Institute for Health Information's (CIHI's) mandate is to improve the health of Canadians and the health care system by providing unbiased, credible and comparable information for better informed decisions. Our vision is to enable better data for better decisions, leading to healthier Canadians.

Currently, use of EMR data for performance measurement and reporting poses some challenges. The predominance of free-text/unstructured data, incomplete data and data inconsistency (for example many ways to say smoking history) lead to limitations in data comparability for analysis and quality improvement. To overcome these challenges, CIHI led the development of PHC EMR Content Standard (PHC EMR CS) in collaboration with Canada Health Infoway and jurisdictions $(1,2)$. Specifically, the PHC EMR CS includes the data elements, reference sets and data extraction specifications. While CIHI developed and maintains the data elements and data extract specifications, Canada Health Infoway developed and maintains the reference sets. The combination of these standards begins to enable the capture of priority EMR data in a structured format so that data can be extracted. This priority data can then be used to support comparable analysis and reporting as well as interoperability to support care coordination between providers.

It is anticipated that up to $23 \mathrm{PHC}$ quality health indicators(3) may be calculated and reported with the implementation of the PHC EMR CS. 
These quality indicators can be used to inform access, PHC prevention, screening and chronic disease management and outcomes. Performance measurement on asthma management can be supported by a subset of PHC EMR CS data elements. PHC EMR CS has the potential to support monitoring and reporting of asthma/COPD incidence, prevalence, $\mathrm{PHC}$ visit use by asthma/COPD patients, monitor asthma/COPD medication use, track FEV1 tests, track wait-times for pulmonologist referrals and promote team-based care for respiratory management.

Insights from EMR data collection and with clinicians participating in the CIHI's PHC Voluntary Reporting System(4) have highlighted the value of the PHC EMR CS to facilitate comparative analysis within and across practices. Once implemented, the PHC EMR CS may support quality improvement, decision making and performance measurement at multiple levels.

\section{REFERENCES}

1. PHC EMR Content Standard Indicators Information Sheet. $<$ http://www.cihi.ca/phc> (Accessed on May 31, 2013).

2. PHC EMR Content Standard Expected Benefits.

$<$ http://www.cihi.ca/phc> (Accessed on May 31, 2013).

3. PHC Quality Health Indicators. <http://www.cihi.ca/phc>

4. Canadian Institute for Health Information Primary Health Care

Voluntary Reporting System (CIHI PHC VRS) 2013.

$<$ http://www.cihi.ca/phc $>$ (Accessed on May 31, 2013).

\section{8}

\section{ADVANTAGES AND CHALLENGES OF USING A WEB PORTAL FOR DATA COLLECTION}

M Diane Lougheed MD MSc ${ }^{1,2,3,4}$, Ann K Taite BSc $^{1,4}$

${ }^{1}$ Department of Medicine; ${ }^{2}$ Department of Public Health

(Epidemiology); ${ }^{3}$ Adjunct Scientist, ICES-Queen's, Queen's

University; ${ }^{4}$ Asthma Research Unit, Kingston General Hospital,

Kingston, ON

Electronic data entry systems are increasingly being used to collect clinical data for research, including performance evaluation. Internet sites that provide access to data entry systems are termed 'web portals'. This abstract summarizes types of research portals, and key advantages and challenges of using a web portal for data collection.

In broad terms, research portals may be categorized as generic or projectspecific. The Research Electronic Data Capture (REDCap) Portal is an example of a software solution with generic and customizable templates (1). Project-specific portals, as the title implies, are designed and programmed to meet the needs of specific studies. Examples of latter are the Better Outcomes Registry \& Network (BORN Ontario)(2), Cystic Fibrosis Canada's on-line electronic data collection system for the CF Patient Data Registry(3) and AsthmaLife, a regional portal developed to provide patients and providers access to education and management resources(4), including validated electronic quality of life questionnaires(5) and Primary Care Asthma Performance Indicators (PC-API)(6).

Advantages of web portals are numerous. Web-portals enable data collection at the point of 'care', which enhances efficiency by avoiding the need for duplicate data entry. The ability to apply data definitions, data standards, and range limits also enhances data accuracy, and in turn minimizes the cost of data 'cleaning' during analysis. Built-in decision support prompts and alerts can help minimize missing data. Timeliness of data collection is also enhanced, as typically data monitoring, collation, analysis and reporting are expedited. Portals are widely accessible, with the main limitation being reliable access to the internet. Web-based portals may now also be accessed via portable devices such as tablets and Smartphones, potentially obviating the need for patient 'study' visits. Portals may be customized to the specific project and by virtue of being potentially paperless, are 'environmentally friendly'.

However, web-portals also pose a number of challenges for data collection. Recently, Koch et al. identified technology literacy and ethical and regulatory frameworks for information sharing as two of the most important challenges(7). Ensuring that privacy, security and confidentiality issues meet regional and national regulatory requirements are paramount. Intermittent internet access, particularly in rural and remote areas, and variable access according to web browsers and versions are commonly encountered barriers. Additional considerations include the impact on work-flow, time constraints of integrating electronic data entry into the process of care, and costs of purchasing, supporting and maintaining servers as well as paying personnel for data entry.

\section{REFERENCES}

1. Harris PA, Taylor R, Thielke R, Payne J, Gonzalez N, Conde JG. Research electronic data capture (REDCap) - a metadata-driven methodology and workflow process for providing translational research informatics support. J Biomed Inform Apr 2009;42 (2):377-381.

2. BORN Ontario About BORN 2013. <http://www.bornontario.ca/ about-born> (Accessed June 17, 2013).

3. Cystic Fibrosis Canada. CPDR On-line 2013. <http://www.cysticfibrosis. ca/en/treatment/CPDROn-line.php> (Accessed June 17, 2013).

4. Taite AK, Olajos-Clow JG, Minard JP, Flavin M, Zielinski D, Lougheed MD. Promoting evidence-based asthma care and knowledge translation (PEACKT): Identification of the needs of patients and parents of children with asthma in a regional asthma network. Am J Respir Crit Care Med 2011;183:A2923.

5. Olajos-Clow J, Minard J, Szpiro K, et al. Validation of an electronic version of the Mini Asthma Quality of Life Questionnaire. Respir Med May 2010;104(5):658-667.

6. To T, Guttmann A, Lougheed MD, et al. Evidence-based performance indicators of primary care for asthma: A modified RAND Appropriateness Method. Int J Qual Health Care Dec 2010;22(6):476-485.

7. Koch S, Vimarlund V. Critical advances in bridging personal health informatics and clinical informatics. Yearb Med Inform 2012;7(1):48-55.

\section{9}

\section{QUALITY INDICATORS AND PRIMARY CARE, ARE WE READY?}

\section{Alan Kaplan MD CCFP(EM) FCFP CFPC}

Family Physician Airways Group of Canada; Department of Family and Community Medicine, University of Toronto, Toronto, ON

Family Physicians want to make and keep their patients well in a time cost effective manner. Real barriers exist to optimized care. Primary care models for compensation continue to change. New(1) graduates are less career-oriented and more family-oriented. Time pressure is real everywhere, with a presumed shortage of physicians in our country, although the numbers do not quite bear that out(2). Paperwork grows unendingly impeding time for care. Relationships between specialists and primary care physician are deteriorating, be them issues of money, prestige, autonomy, power and others(3).

Asthma control in Canada is suboptimal(4). The provision of defined asthma quality indicators(5) could assist in this by providing a framework for asthma care. These indicators have to be easily measureable to assist in the assessment of efficacy of instituting quality indicators in practice. Reward systems for appropriate care occurs in the UK, wherein payments are dependent on fulfilling criteria indicating measures of control, lung function, education and device technique. These criteria need to be incorporated in chronic disease management strategies here also; wherein the patient is in the centre of the model and supported by the medical system. The CFPC is championing the concept of the "Patients' Medical Home(6)" with all care orchestrated by the primary care team. We need the support of EMR vendors in creating programs that are accessible and interactive while sustaining electronic tools for primary care management which would include quality indicators. The Family Physician Airways Group of Canada website (www.fpagc.com) has multiple tools to support asthma management in primary care including asthma action plans and asthma flow sheets for diagnosis and management. Quality indicators in tools such as these should assist us with our primary goal, to improve asthma management in Canada.

\section{REFERENCES}

1. Buddeberg-Fischer B, Stamm M, Buddenberg C, Klaghofer R The new generation of family physicians -career motivation, life goals and work-life balance. SWISS Med Wkly 2008;138(21-22):305-312.

2. $<$ http://www.cihi.ca/cihi-ext-portal/internet/en/document/ spending+and+health+workforce/workforce/physicians/ release_15nov12> (Accessed April 30, 2013).

3. Pearson S. Principles of Generalist-Specialist Relationships J Gen Intern Med. 1999 January; 14(S1): S13-S20.

4. FitzGerald JM, Boulet LP, McIvor RA, Zimmerman S, Chapman KRAsthma control in Canada remains suboptimal: the Reality of Asthma Control (TRAC) study. Can Respir J 2006 Jul-Aug;13(5):253-9. 
5. To T, Guttman A, Lougheed D, et al. Evidence-based performance indicators of primary care for asthma: A modified RAND Appropriateness Method. Int J Qual Health Care2010 Dec;22(6):476-85.

6. <http://www.cfpc.ca/A_Vision_for_Canada/> (Accessed May 1, 2013).

\section{0}

\section{LAYING THE FOUNDATION FOR PRIMARY CARE} PERFORMANCE MEASUREMENT IN ONTARIO

Brian Hutchison MD MSc CCFP FCFP, Michelle Rey PhD,

Wissam Haj-Ali MPH CPH, Saurabh Ingale MHA

Health Quality Ontario, Toronto, ON

Health Quality Ontario (HQO) is an independent government agency, created under the Commitment to the Future of Medicare Act(1) on September 12, 2005. The Excellent Care for All Act(2) was passed in the legislature expanding Health Quality Ontario's role and mandate on June 8 , 2010. In line with its mandate to monitor and report to the people of Ontario on health system outcomes, HQO is leading the Ontario Primary Care Performance Measurement (PCPM) initiative(3).

Objective: Ontario lacks a system-wide, sustainable approach to measure primary care performance, an essential requirement for managing and improving performance at the practice and system levels. HQO is collaborating with other stakeholders through the Ontario PCPM Steering Committee* $^{*}$ to provide leadership on a coordinated and sustainable approach to measure and report on primary care performance.

Approach: An environmental scan was conducted to examine the current state of primary care performance measurement in Ontario, throughout Canada, and internationally. Informed by the scan, aspects of primary care performance across nine domains were identified as potentially valuable to measure on a regular basis to inform decision-making at the practice and system levels.

A Primary Care Performance Measurement Summit was held with senior leaders from key primary care data partners and information users in Ontario in 2012. Summit attendees ranked the potential areas of performance measurement through a voting process. A survey was circulated among primary care stakeholders to validate and further refine the initial set of potential performance measurement priorities.

NEXT STEPS: Guided by the Steering Committee, the Summit results, and broad stakeholder engagement through the stakeholder survey, two sets of performance measurement priorities, one addressing the practice/ organizational level and the other addressing the system (community, regional, provincial) level, will be finalized in summer 2013. Supported by the Steering Committee, working groups will be established to propose specific measures corresponding to the identified performance measurement priorities and a technical working group will identify appropriate data sources and make recommendations regarding the infrastructure needed to support data collection, analysis and reporting.

CONCLUSION: The emerging set of performance measures, developed through broad stakeholder engagement, will be an important step toward a comprehensive, coherent performance measurement framework to support the planning, management and continuous improvement of primary care in Ontario at both the practice and system levels. Over time, the framework will be updated in response to changing performance measurement priorities and significant changes in the province's strategic direction.

\section{REFERENCES}

1. Ontario Regulation 14/05 made under the Commitment to the future of Medicare Act, 2004. The Ontario Gazette. 2005 February 19. < http://www.e-laws.gov.on.ca/html/source/regs/english/2005/elaws_src_ regs_r05014_e.htm> (Accessed June 14, 2013).

2. Ontario Ministry of Health and Long-Term Care. Excellent Care for All Act- Health Quality Ontario 2012. < http://health.gov.on.ca/en/ pro/programs/ecfa/legislation/hqo.aspx> (Accessed June 14, 2013).

3. Health Quality Ontario. Primary Care. 2013. <http://www.hqontario. ca/public-reporting/primary-care> (Accessed June 14, 2013).

*ORGANIZATIONS REPRESENTED ON THE PCPM STEERING COMMITTEE: Association of Family Health Teams of Ontario, Association of Ontario Health Centres, Canadian Institute for Health Information, Cancer Care Ontario, Cancer Quality Council of Ontario, C-CHANGE Initiative, eHealth Ontario, Health Quality Ontario, Institute for Clinical Evaluative Sciences, Local Health Integration Networks, Ontario College of Family Physicians, Ontario Medical Association, Ontario Ministry of Health and LongTerm Care, Ontario Patient Relations Association, Patients' Association of Canada, Registered Nurses' Association of Ontario.

\section{AUTHOR INDEX}

\section{$\mathrm{C}$}

Côté B ....................... 2

$\mathrm{D}$

Doucet M.................... 2

$\mathrm{H}$

Haj-Ali W ..................... 10

Hutchison B. ................. 10

I

Ingale $S \ldots \ldots \ldots \ldots \ldots \ldots \ldots$
K

Kaplan A ................... 9

$\mathrm{L}$

Lougheed MD ............... 8

$\mathrm{N}$

Nath U....................... 3

$\mathbf{P}$

Pouliot $\mathrm{S} \ldots \ldots \ldots \ldots \ldots \ldots \ldots 2$

Q
$\mathbf{R}$

Ramsey CD .................6 6

Rey M................... 10

$\mathrm{S}$

Simatovic J. ...................1,4

Sullivan-Taylor P................ 7

$\mathrm{T}$

Taite AK ..................... 8

To T .......................1,4

Tousignant $\mathrm{P} \ldots \ldots \ldots \ldots \ldots \ldots \ldots$ 


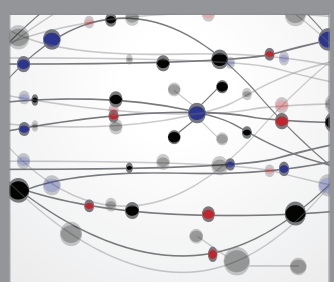

The Scientific World Journal
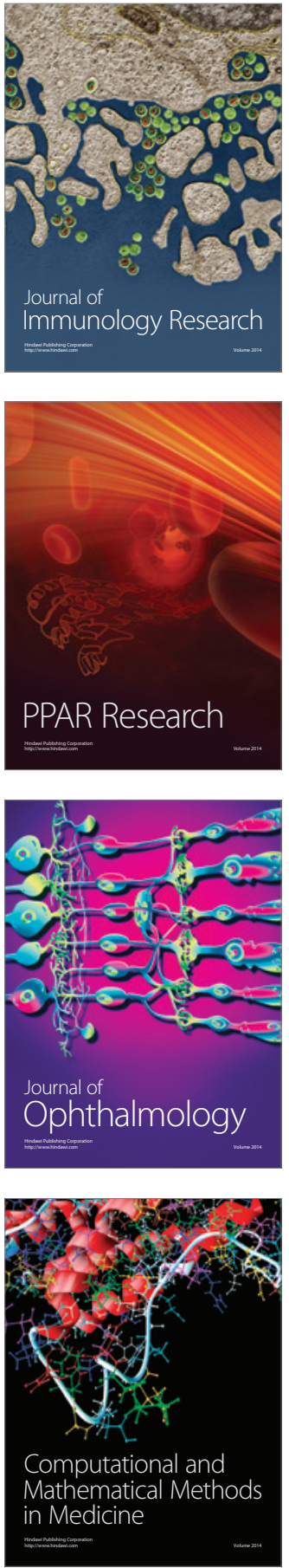

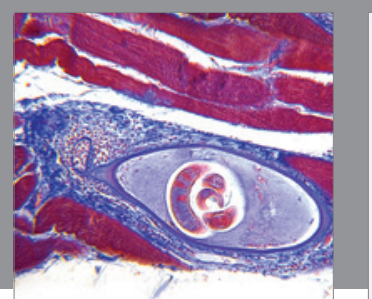

Gastroenterology Research and Practice

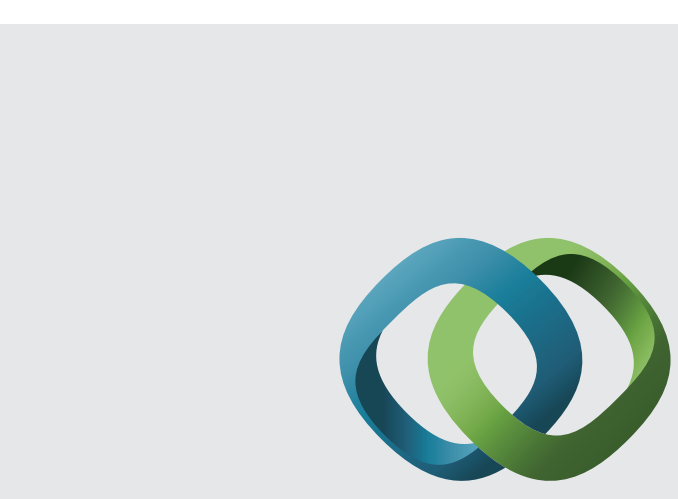

\section{Hindawi}

Submit your manuscripts at

http://www.hindawi.com
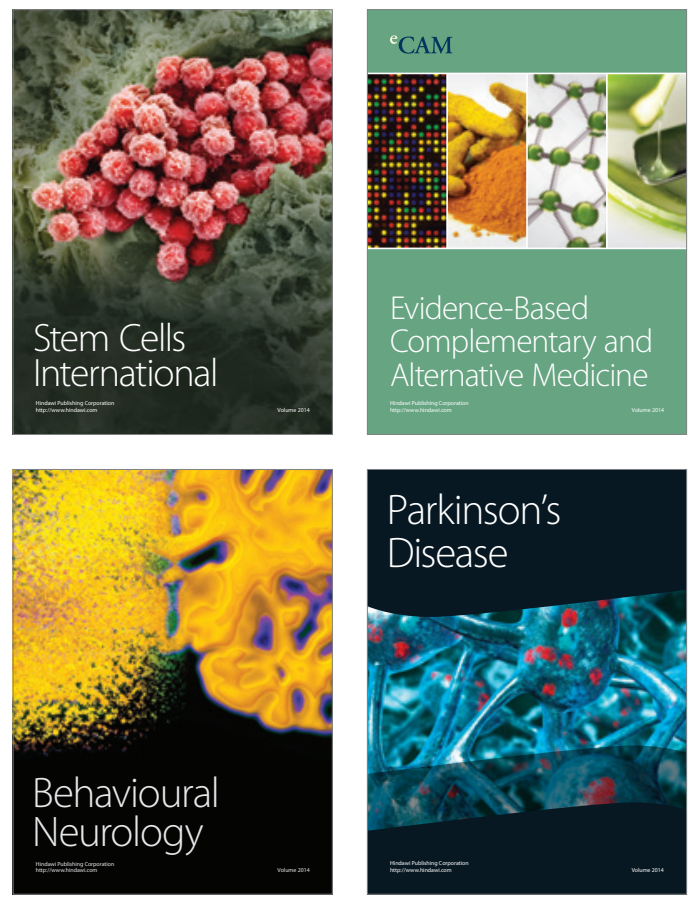
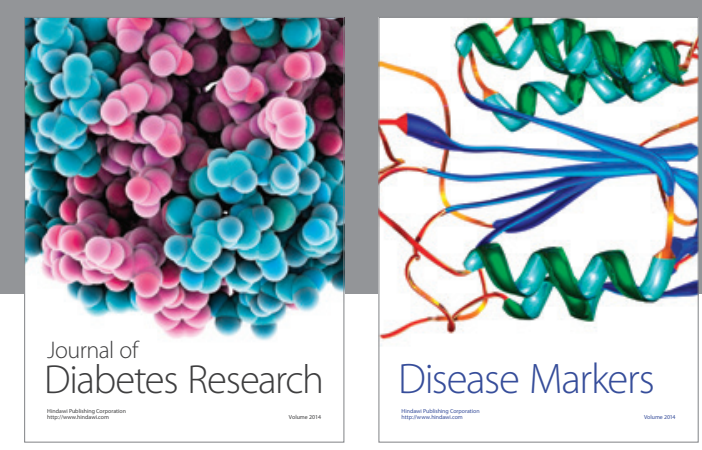

Disease Markers
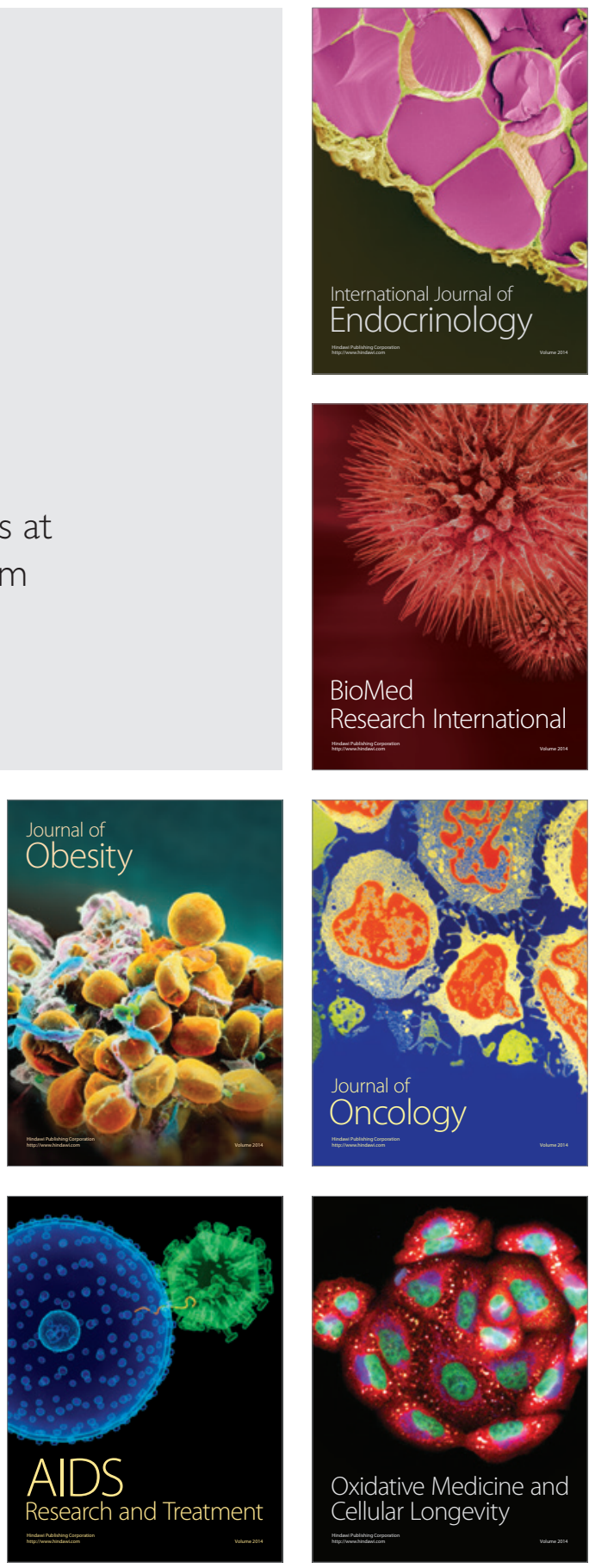